First Peoples Child \& Family Review

A Journal on Innovation and Best Practices in Aboriginal Child Welfare Administration,

Research, Policy \& Practice

\title{
The Impact of Poverty on First Nations Mothers Attending a Parenting Program
}

\section{Barbara Harris, Mary Russell and Annemarie Gockel}

Volume 3, Number 3, 2007

URI: https://id.erudit.org/iderudit/1069394ar

DOI: https://doi.org/10.7202/1069394ar

See table of contents

\section{Publisher(s)}

First Nations Child and Family Caring Society of Canada

\section{ISSN}

1708-489X (print)

2293-6610 (digital)

Explore this journal

Cite this article

Harris, B., Russell, M. \& Gockel, A. (2007). The Impact of Poverty on First Nations Mothers Attending a Parenting Program. First Peoples Child \& Family Review, 3(3), 21-30. https://doi.org/10.7202/1069394ar

\section{Article abstract}

Urban Aboriginal mothers' experiences with Family Preservation Services indicate that while such interventions ameliorate the challenges they face, poverty is not adequately addressed. Prominent are the importance of prevention; attention to process; cultural context; and attention to actual needs, however, First Nations mothers (a) feel lucky when they get things they need, (b) feel 'inadequate' about the inability to manage finances, and, (c) perceive the lack of support in meeting needs to be a result of racism. As well, poverty often leads to forced compromises which can perpetuate risk of coming to the attention of child welfare.
Copyright @ Barbara Harris, Mary Russell, Annemarie Gockel, 2007
This document is protected by copyright law. Use of the services of Érudit (including reproduction) is subject to its terms and conditions, which can be viewed online.

https://apropos.erudit.org/en/users/policy-on-use/ 


\title{
The Impact of Poverty on First Nations Mothers Attending a Parenting Program
}

\author{
Barbara Harris $^{a}$, Mary Russell ${ }^{b}$, and Annemarie Gockel ${ }^{c}$
}

\begin{abstract}
${ }^{a}$ Barbara Harris, MSW, RSW, and Ph.D Candidate, is of Dene heritage. She is the First Nations Advisor and a Lecturer at the UBC School of Social Work \& Family Studies. Research interests include urban Aboriginal women's experiences with addiction services, Aboriginal social work education and curriculum, and evaluation of services to First Nations.

Address: UBC School of Social Work \& Family Studies, 2080 West Mall, Vancouver, B.C. V6T $1 Z 2$

Office: (604) 822-6622 Fax: (604) 822-8656

Email: bharris@interchange.ubc.ca

${ }^{b}$ Dr. Mary Russell is a Professor at the UBC School of Social Work \& Family Studies. Her research areas have included family violence, client feedback, and services for high-risk parents. Her practice areas include family violence and mental health.

Address: UBC School of Social Work \& Family Studies, 2080 West Mall, Vancouver, B.C. V6T $1 Z 2$

Office: (604)-822-2794 Fax: (604)-822-8656

E-mail: mrussell@interchange.ubc.ca
\end{abstract}

${ }^{C}$ Annemarie Gockel, MSW, and Ph.D. Candidate (UBC, Department of Educational and Counselling Psychology). Her research includes high-risk parents, spirituality, and substance abuse. She was program manager as well as clinician in addiction services for many years.

Address: 306-1549 Kitchener St., Vancouver, B.C. V5L 2V8

Phone: (604)-258-4146

E-mail agockel@telus.net

\section{Introduction}

Parenting programs are an element of Family Preservation Services (FPS), which may be home based, or community based, and include a variety of educational, practical, and supportive resources aimed at mitigating or reducing risk of child abuse and neglect, without removing children from their

\begin{abstract}
Urban Aboriginal mothers' experiences with Family Preservation Services indicate that while such interventions ameliorate the challenges they face, poverty is not adequately addressed. Prominent are the importance of prevention; attention to process; cultural context; and attention to actual needs, however, First Nations mothers (a) feel lucky when they get things they need, (b) feel 'inadequate' about the inability to manage finances, and, (c) perceive the lack of support in meeting needs to be a result of racism. As well, poverty often leads to forced compromises which can perpetuate risk of coming to the attention of child welfare.
\end{abstract}

homes. However, although there have been increases in family preservation services, apprehensions are still increasing as well (Pelton, 1997). The Federal Provincial Working Group on Child and Family Services Information (2005) reported that between 1998 and 2000 Ontario's children in care (CIC) rose from 12,079 to 16,516; Alberta's CIC's rose from 6,629 to 7,946, and British Columbia's CIC's rose from 12,574 to 14,032 . Additionally, in a review of investigations in Canada between 1998 and 2003, Trocme et al (2003) found an increase of $125 \%$ in substantiated cases of maltreatment, a pattern which echoes Petlon's conclusions.

In an Aboriginal context as well, apprehensions are not subsiding, yet this cannot be adequately explained by the above mentioned trends. Walmsley (2005) notes that while less than $1 \%$ of British Columbia's CIC's in 1955 were Aboriginal, by 1964 the number had jumped to $34.2 \%$. Currently, some regions report that up to $80 \%$ of CIC's are Aboriginal (Trocme, Knoke and Blackstock, 2004). Blackstock, Trocme and Bennett (2004) note that 
Aboriginal children are overrepresented, investigations are more likely to be substantiated, cases are more likely to be kept open for ongoing services, and children are more likely to be placed in out of home care (p.901).

Pertinent are the links between colonization, poverty and apprehension of Aboriginal children (Walmsley, 2005; Mandell, et al, 2003; Blackstock, Trocme and Bennett, 2004; Fox, 2004; Trocme, Knoke and Blackstock, 2004; McKenzie and Hudson, 1985). From residential schools, to the 60's scoop, to modern day child welfare, the agenda of assimilation continues. While Aboriginal agencies are moving towards greater control over child welfare (Bennett, n.d.; Timpson, 1995), a reduction in rates of placements "may not occur until resources are allocated to address the social problems that undermine parents' abilities to care adequately for their children" (p. 596).

In terms of parents' abilities to care for their children, the relationships between Aboriginal mothers and child welfare authorities are further clouded by a mainstream ideology of motherhood, whereby "individual First Nations women are blamed for the difficulties they experience in child raising...[with little or no attention to]... the history and current dynamics of colonialism and racial oppression" (Kline, 1993, p. 306). Kline argues that these dynamics are fundamental to the overrepresentation of Aboriginal children in out of home care and further adds that privileging mainstream ideology of child rearing undermines and invalidates Aboriginal parenting practices and traditions.

In reference to research, Blackstock et al (2004) note that progress is limited in terms of developing data on services to families involved with nonAboriginal child welfare authorities, that there is a lack of qualitative research on Aboriginal families within child welfare, and that research should include "Aboriginal child welfare agencies and mainstream agencies...."(p. 175).

Additionally, there is limited research on Aboriginal peoples' perspectives on prevention and support services. In a philosophical analysis of how FPS could be developed to serve Aboriginal clients, Coleman, Unrau and Manyfingers (2001) describe the need to attend to the different conceptions of family, time, parenting and spirituality, but also argue that "focusing exclusively on the family without addressing larger social concerns perpetuates notions of pathology" (p. 66), while Anderson (1998) argues for a more prominent focus on family support versus apprehension.

Unfortunately, government cuts to income relief and to family preservation services during the period of the study indicate a general lack of commitment to poverty stricken families, and lack of concern about perpetuating the risks that child welfare and FPS supposedly seek to avoid. While an understanding of Aboriginal mothers' experiences with different aspects of child welfare is needed, this analysis provides important insight into urban Aboriginal mothers' experiences while attending mainstream family preservation services, and highlights the impact of poverty among these mothers. The findings indicate a need to reverse the current status of FPS, which has minimal priority within child welfare, and to restructure social services in order to eradicate poverty.

\section{Context Of The Study}

The data being reviewed here is based on a sub-group of participants in a longitudinal study of parent experiences with Project Parent, a program provided by Family Services of Greater Vancouver. The program provided intensive services to parents whose children were considered to be at risk of abuse or neglect by child protective services. Parents with young children attended the program at the centre for two days per week, while other parents received inhome visits as well as attending group programs at the centre. Transportation, meals and child care were provided. Individual counseling, parent education groups, coaching and modeling of positive parenting techniques, introduction to community resources, goal setting, and advocacy with other services were components of services provided. Program duration ranged from 3 months to 1 year. Families were followed through the program and for a period of up to one year after exiting the program. Of the 35 families involved in the study, six were headed by Aboriginal mothers, and of 115 interviews, 19 (16.5\%) were conducted with this group; two participants were interviewed six times over a one and a half year period, one was interviewed four times, and three were interviewed only once. All six families in this report were living in poverty, and were in receipt of Income Assistance. Five of the mothers were living on their own, while 
one had a live-in partner at the time of the study. Four of the mothers lived in commercial rental housing, while 2 lived in designated aboriginal accommodation. Two of the mothers completed high school, with four reporting only partial completion. Five mothers reported being victims of family violence, while four had addiction related issues.

While the findings may not be generalized to all urban First Nations women who come into contact with FPS, these 19 interviews provide a keen insight into issues faced by this population, including the impact of poverty. Importantly, the quotes are not restricted to experiences with FPS - rather, they reflect these women's lived experiences during their interactions with FPS.

\section{Results}

In reviewing Aboriginal mothers' experiences while attending Project Parent, the two prominent themes related to perceptions of services they have accessed, and of living in poverty. Aboriginal mothers expressed interest in prevention, paying attention to process, addressing needs, and cultural context. However, compounding the challenges that Aboriginal mothers face in caring for their children is the issue of poverty. As well, poverty leads to forced compromises which can perpetuate the risk of contact with child welfare services.

\section{Prevention}

Prevention is an important priority among Aboriginal mothers who want to overcome the historical patterns arising from colonization, to create healthy environments for their children, and to get the emotional support they need. First, it is important to realize the relationship between history, and the current realities, which include a lack of needed role models, and a lack of confidence in ability to parent. Parents do, however, want to break the cycle, and give their children what they need.

I'm not looking for someone to have all the
answers in my life, I'm just saying how can
I deal with my daughter in a positive way
that's not like what I've seen growing up.
I've learned a lot about: number one, my
dysfunctional behavior ... you only do what
you know and sometimes you don't know a
lot because you weren't taught a lot from your own parents. I never had help before ... someone to show me how to parent.

Watching my girlfriend, helps me to realize I can do it, and at the end of the program, it made me have more confidence in myself.

Being aware of and acknowledging the intergenerational impact of colonial policy on Aboriginal families can help prevent the tendency to blame these mothers for their lack of skills and knowledge in parenting their children. For these mothers, history is a motivator.

Another concern among urban Aboriginal mothers is the environments which their children are exposed to. Minimizing the negative impact of the environment on children involves considering safety and security.
I'm really big on location ... there's a lot of programs in the DTES - I'm not prejudice. I've got family down there, but ... I have a hard time bringing her down there, so location is location. I like it here-it's bright, happy, safe.
I need a secure and loving environment. I wouldn't stand in the food lines if I had my kids with me... I wouldn't be taking them down there.
They have been asking me to volunteer, until about 8:30 at night and I'm like 'no, not in that area - it's nasty. I can't imagine commuting home with my daughter at night time like that.

Aboriginal mothers are aware of the influence of the environment on child well-being, and programs need to assist these mothers in ensuring healthy environments in which to parent their children. As will be seen later on, poverty is a crucial factor in relation to creating a healthy environment.

As well, prevention involves emotional support. Isolation is an insidious risk factor permeating the lives of Aboriginal women in a climate of marginalization, and these mothers recognize the risks associated with isolation.

I've already made my mind up - I don't want where someone comes to my house and does Outreach, because that is just going to put me back into that hole again of being depressed ... if I have no one to go to. 
It was better for me because I'd started to get really depressed at home - not having nowhere to go; nobody to talk to.

I preferred my last social worker. He was there more emotionally for me ... because when I was just having a rough day at home, I could call him up and he'd take the time to talk to me...

These mothers want to avoid getting depressed, and view emotional support as a necessary preventive measure.

The interest in preventive measures is a result of urban Aboriginal mothers' awareness of factors that affect their ability to adequately parent their children. They understand that history, environment and emotional support are all factors which influence parenting and ability to function, and it is important to build on these understandings, and support their goals in relation to overcoming historical patterns, creating healthy environments and avoiding depression by providing needed emotional support.

\section{Paying Attention To Process}

Another issue concerns the importance of process versus outcome based interactions that involve collaboration, listening, comfort and continuity, client centered services, and clarity regarding expectations. First, urban Aboriginal mothers prefer collaborative relations, and noticed a change after the cutbacks.

They kind of held my kids over my head, saying, if I don't come here, we'll take your kids. I didn't appreciate that, - I felt like they were holding my kids over my head and saying go or else. I had no choice in the matter.

My social worker put me in here. She didn't force me to be here, but it's something she thought would be best for me and my kids because I'm a single parent with two kids, and then she mentioned here, and I said: okay, I'll try it.

Before they would ask, they would always ask what everyone would like to learn or what we are looking for and then they would set it up for us. They don't do that now.

Importantly, while feeling coerced had a negative impact, all of the mothers expressed an appreciation for Project Parent, and collaborative relationships can prevent hard feelings that may get in the way of helping mothers reach their goals.

Secondly, the issue of not being heard is common in the transcripts, and leads to further difficulties for clients. For example, the first quote in this section was from a mother who was cut off from services as a result of missing meetings with the worker

The reason why Carol is not seeing me no
more - is because of missed appointments.
And I said: well, I've asked you to remind
me - maybe the day before, but she would
call me on the day of the appointment,
and the worst part of it is the days that I
did have to see her would fall on Welfare
Wednesday, which is the day I need to go
and get groceries, because we are probably
all out by cheque day. It may not look like
we are struggling, but we are. I just need
a little bit of a support system, to say: I'm
there tomorrow... not, I'm here now!

Alternatively, when service providers don't listen, clients are frustrated, and sense a lack of caring or concern.
I've asked my social worker to come with me, more than 4 times. He's never come with me. And I told him that I feel like I'm at my wits end here... I feel like as much as I ask you all for help, it don't seem like I'm getting it.

It is important to recognize that clients don't just want to be heard - they want congruent action. In both cases above, the participants felt unheard based on the inaction of service providers. The indication is that if a service provider did hear the client, and can't oblige the request, they need to - at the very least inform the client of the situation, versus simply not acting. Clients are all too aware of the failure to listen and act on their behalf.

An additional concern related to feeling comfortable, and having continuity with staff and clients. Given the sordid history of social workers in the lives of Aboriginal families, it is understandable that establishing comfort takes time. Noticeable in these quotes is the affect of cutbacks to funding that led to a reduction in programming.

I wish we could have it the way we had it because it was so comfortable and we talked about what everybody wanted and what they needed help with and we would 
have enough time to just talk about what is going on in our lives.

If I were to run something like that the first day would be trying to kind of know each other ... I want to feel comfortable and not just have total strangers and just blather out what is going on in my life. And they don't do that.

In our new parenting program we only have two people that I knew from there, we have a whole new crew and that's what makes it uncomfortable. At our old place it was the same people everyday.

Developing comfort takes time, and continuity provides comfort in sharing their concerns with other participants and staff. Importantly, these comments show the negative impact of service cutbacks on urban Aboriginal mothers. Apparent is the need to consider the importance of program continuity when making decisions about funding.

Urban Aboriginal mothers also appreciate client centered services that are structured, and provide practical skills in parenting. In the case of the former, structure helps maintain focus.

The people in the program now are not very focused and he doesn't seem in tune with what's going on, so it's a lot different. He doesn't have control over the group ... he just lets everything slide. That's what totally screws it up. It will just slide right off subject and there goes the whole day.

One final factor relevant to paying attention to process is that urban Aboriginal mothers described challenges related to clarity of expectations.

There's a lot of requirements required of me to - in order to get my children back - they don't really tell me directly what is expected of me - I kind of have to go around doing what I think they expect of me, in hopes that is what they want. I found that to be a big struggle but there's not really a lot of communication between us. They have their agenda that they have to fulfill-and because my kids are in care, I don't really know what that agenda is. They don't directly tell me what it is ...

Clear communication of expectations will assist mothers in understanding what they need to do to be able to move beyond their current status with child welfare agencies.
Overall, paying attention to process includes collaborative relationships, listening and acting, comfort and continuity, client centered services, and clarity regarding expectations. These issues indicate the importance of relationships between clients and service providers, and imply a need for respectful, sensitive interactions which can enhance successful outcomes.

\section{Cultural Context}

From a cultural perspective, parents expressed the importance of cultural continuity, butalso discussed the cultural conflicts they experience as urban Aboriginal women. First, the importance of identity and culture is evident among urban Aboriginal mothers, who value the ability to foster their children's cultural identities.

She has to know, ... who she is and what her back ground is ... when I grew up I never had any of that so I just want to teach her to be proud of who she is.

Very good genealogical graphing and that was really interesting and helpful, and that's good for the kids. I can go through those later on and explain to my kids - I can explain their line to them - who their family is. That's important for them.

Additionally, these mothers also appreciate access to cultural activities, which assist them in their own wellness and healing.

With the counselor there was a lot of spiritual teachings... every time I went to see him I was learning so much about myself and the medicine wheel. It's like an unwritten or unspoken teaching to balance ourselves on the wheel - emotionally, spiritually, physically and mentally - that is something we always strive for and I was getting all of that from working with this individual. I think I was resenting the fact that I could no longer see this person.

I am going to a ceremony this week ... there's praying and drumming and singing ... It can be really healing because a lot of times I'll walk out of the Lodge feeling pretty A-ok - pretty relaxed.

I was given a name ....I was so thankful because for me it was like a sense of relief that now I don't have to worry about relapsing again. I'm not saying that name is 
going to save me from doing that, but it just

gives me that much strength.

Access to cultural resources can enhance urban Aboriginal mothers' ability to progress through the system successfully by providing a focus on healing and wellness, while reducing stress.

Furthermore, Urban Aboriginal mothers also appreciate Aboriginal service providers' familiarity with their specific needs and issues. There is a sense of common history that doesn't need to be explained, and which can facilitate a bond with workers.

They understand more because they are First Nations, whereas [in the] other one if I said something they would be asking all these million of questions and I don't want to get into it.

First Nations it's easier ... we all come from the same history so we have a lot in common.

The social worker I have - it's a lot easier because she only works with First Nations ... she knows more of my history so it's a lot easier for me and her to have a bond.

Thus cultural continuity involves teaching the children who they are and where they come from. For the mothers, ceremonies provide them with strength and comfort, and access to cultural resources/services provides a needed familiarity.

Secondly, for Aboriginal women, living in an urban setting involves cultural conflicts. One mother expressed the challenge of figuring out how she would provide her children with a sense of their father's cultural identity - Spanish, and her own side - First Nations.

\begin{abstract}
I'm not sure which way I want to teach them. Last year we were going to Powwows all year round - so that's something I want to keep up ... I know in the Spanish culture the big thing is going to church on Sundays. That's something my culture doesn't do.
\end{abstract}

Another mother discussed the conflict between her and her mother, who abandoned her at an early age. As a result, she doesn't identify with her mother's culture, which leads to conflict in their relationship.

She tries to tell me to do cultural things on her side of the family, cultural stuff from where she comes from and why should I. I was never raised there. I'm not with your band so why should I follow your traditional teaching.

As well, one mother feels alienated from her family, who are living on reserve.

\begin{abstract}
And here is L, single mum, in the city, in Vancouver - bi-racial who is not full Native ... They can't relate to me. They don't relate to me paying my bills by myself, or feeding myself and not needing them.
\end{abstract}

None of the clients described opportunities to address concerns related to cultural conflict with service providers, yet being able to understand and negotiate these conflicts is an area of concern for these mothers.

\section{Addressing Needs}

In terms of needs, the main issues are accessibility, and help with basic needs. First, in terms of accessibility, parents appreciate transportation, and flexibility, but also want ongoing access to services. Importantly, providing transportation affects attendance in programs.
One of the thing that I like is that they have extra bus tickets to get me here and there, and if I don't have any bus tickets they provide a ride or make arrangements for me to get a ride - like this morning I didn't have any bus tickets or money to get here so they arranged for a ride.
They helped me - they are just very on the ball with how the rides are going to work out. Like if my kids are sick during the day they'll make sure to phone early enough to let me know that my kids are sick and I won't come in that day. Well organized.

Flexible access means that parents can get immediate assistance when they need it, but also relates to policies which limit access. Flexible access to services when they're needed reduces stress.
It was so nice there ... I could go to anybody if I needed help ... and they could help me right away. Just knowing that they're there it's a big load of your shoulders, but now that they are not there it is hard, it is really hard.
I'll be getting another family support worker, but she only works Thursdays and Fridays, and I need a support worker that can help me all the other days. 
Urban Aboriginal mothers also appreciate flexible eligibility criteria that don't have age limits, and that allow the whole family to be involved. Such criteria for participation may be viewed as a funding issue, but also affect interest in attending.

It's kind of hard because of their age groups and they will only take kids for eighteen months and younger and she past that so it's really hard ... because of the cut backs a lot of them have age limits.

I didn't bother looking in to it because of where it is at ... and besides, men aren't allowed in it ...

Additionally, the need to maintain access to services on an ongoing basis, provides a sense of security.

I want to have something to lean on if I breakdown or something.

My social worker wants to close my file because I'm doing so good, but it sucks ... because I lose all my services, I don't get a bus pass, and I'll lose my social worker. I don't want to be stranded.

Thus, access to services affects attendance, reduces stress, and provides security.

As well, these mothers stress the need to learn new skills that will reduce difficulties in parenting. For example, improving communication alleviates frustration. Alternatively, while mothers want to know about developmental stages, asking for help and not getting it increases frustration.

\begin{abstract}
It is just so much easier to communicate with her now, not trying to guess what's wrong with her. She can tell us what's wrong... before you were always trying to guess what was wrong with her and now she can tell us what is going on.

I was asking for support ... about her stages ... how to deal with her. But for the main part ... my worker basically reiterated things that I already know, so it made me feel kind of like I was spinning my wheels... it didn't really seem to go too far and ... that's not really helping me in the sense that I need.
\end{abstract}

As mentioned earlier, urban Aboriginal mothers want help in this area, in order to effectively parent their children. This involves behavioral and cognitive strategies such as age appropriate discipline, and setting healthy boundaries, as well as simply improving communication. Ongoing feedback from clients can help ensure they're gaining the skills they need.

Secondly, parents especially appreciated help with basic needs. Many services are required that reduce the challenges of poverty including, for example, access to a phone, and clothing.

I use the phone here a lot because I don't have a phone. I use the phone, usually before and after my sessions when I'm here at Project Parent. If I have any faxing, like the support letters or personal letters for myself, say resumes or something like that, I have free access to fax services. Yes, so that's quite a bit.

She showed me the clothing room ... which was really helpful, because my girl is still using the clothes. And it's nice like that ... it's helpful.

It is also important to understand how adherence to policy can have a negative impact on clients and create further hardship in stressful times.

The first month that they were here they knocked off $\$ 350$ for support which is for food ... because of bureaucracy with the Court I wasn't supposed to get anything more than that until I had something called a "supervision order document"... that could be passed to my financial aid worker. That didn't happen, so I didn't get the remaining of my supports. It was a real challenge for all of us to adjust to that part right there.

We're financially stuck right now, welfare isn't giving me anything. I am really stuck .... I am stressing right now because they're at the end of their milk, they're hungry because we have no food. The worker wanted a letter from my husband's work ... but I can't get a hold of his boss ... so she turned around and closed my file.

Furthermore, mothers fear repercussions if they aren't able to provide for their children.

I think it was two times I asked for a bed for her and for myself, and they turned it against me and split up my cheque ... saying you've exceeded the limit amount for some crisis grant. I said: excuse me, you want my daughter sleeping on the floor so you can call social services and have them take her? They didn't really get it. 
Ultimately, the issue of poverty permeates the lives of this client group, and it is especially important to become aware of, and address poverty.

\section{Understanding The Impact Of Poverty}

A closer look at poverty in the lives or urban Aboriginal mothers indicates that these mothers (a) feel lucky when they get things they need, (b) blame themselves for financial difficulties, and (c) feel that the failure to get needs met is due to racism. Importantly, the reason social services exist is because of a belief that people have a right to a basic standard of living. Yet, these mothers lack a sense of entitlement, and feel lucky when they get things they need.

The foster parent brings them here, and then on the Tuesdays I just get my own way there ... I've been just lucky - I've had money at the time, so I've been able to get to the visits.

We are a lot more fortunate than other single parent families in that we live in Native Housing so we - if I'm in between jobs, I don't have to worry about it. I don't have to worry about the roof being yanked from us that sort of thing.

Furthermore, these mothers blame themselves for the difficulties in managing their meager finances:

I think I've made a lot of mistakes with my budget ... It was really crazy, like food and bus fare that was about it. But I think you really learn from your mistakes. I think lessons like that - it makes you learn more. Makes you plan more.

I got to learn how to keep money through the whole month. Like I said, we are on social assistance and I spend money that we don't have. It's just me ... my problem. I shouldn't have to struggle as much as I do because of the way that I spend money. And that's buying her extra clothes that she don't even fit yet, but she's got clothing in her closet until she is a teenager, because there may be a time where I say: I just don't have the money.

Ultimately, these mothers interpret the failure to get their needs met to be a result of racism, which permeates their experiences with service providers across disciplines.
It's hard. I'm only half First Nations, but it's hard to be at the point where people don't want to help because people think ... she's just a Native trying to get out from working.

They look at me as if I drink, and as if I use drugs, and I don't buy stuff for my kids ... I've done so much trying to show them that just because I'm Native, we all don't do that.

The doctors that I've been to have been really prejudiced with me ... I'm not your stereotypical First Nations - I'm a real person on welfare.... And I burst in to tears and I said: I'm tired of you people not signing this paper for me because you think I'm a Native who wants not to work. He was just judgmental and didn't sign it.

Last but not least, poverty stricken Aboriginal women have limited choices and have difficulty obtaining adequate housing. As such, they are often forced to make compromises which affect their vulnerability to interactions with authorities including child welfare, due to the negative impact on parenting. Thus, urban Aboriginal mothers find themselves in a CATCH 22 which is a direct result of living in poverty. For example; living with relatives who are still abusive leads to children picking up unhealthy behaviors; sharing a home with family who party at night affects getting adequate sleep; and living in housing where there are other social issues among neighboring families can lead to interactions with police.

Sometimes, her partner would be verbally abusive with her and saying things to her, when they get upset with each other. So out biggest challenge right now with $S$, is her copying those words when she gets frustrated. It's hard.

My partner's uncle - this is his place, so that's how we got here. Their hours are different than ours, so it's hard. They are like night owls and we're not ... so we're going to bed at $10 \ldots$ and they don't get up and start moving around until that time! So when they're sleeping, we are waking up. And they don't walk light upstairs ... so it's kind of hard sometimes.

Someone was calling social workers on me and saying that I was neglecting my children; and that they had no food; and 
that they had no clothes. So I had people at my door investigating me ... you know how many times the cops have come to my house banging on the door demanding that there's a restraining order on me ... And I say: excuse me, you have the wrong door ...leave me the@\#+*alone! It feels like the cops are always banging on my door, looking for someone, trying to tell me it's me ... and I'm like, what the? There's nothing going on here.

Each of the above three quotes indicate scenarios could easily lead to attention from child protection services, as each situation affects the ability to parent their children. It's particularly important to realize that accommodations made due to poverty should not be blamed on these mothers or their capacity to parent. The choices are often a result of poverty, and related to minimizing hardship in meeting other basic needs such as food, and clothing.

\section{Discussion}

While FPS can provide help with basic needs, other stressors can be reduced by facilitating preventive measures. These include assistance with overcoming negative historical patterns arising from colonization, creating healthy environments for their children, and getting emotional support to avoid isolation and depression. Mothers in the current study indicated that they, like the majority of parents, have the best interests of their children at heart, and desire to overcome negative effects of history and environment. Group programs that provide continuous and flexible support as well as culturally relevant experiences were reported as beneficial in this regard by mothers.

In terms of the nature of services, mothers valued the provision of process versus outcome based interactions that include collaboration listening and congruent action, fostering comfort and continuity, and clarity regarding expectations. Mothers reported satisfaction when goal setting was a collaborative process wherein they experienced service providers as clearly listening to their accounts and being helpful in formulating positive strategies. Mothers also valued clear and specific information about expectations and/or requirements in terms of child protection supervision orders, as opposed to the common experience of vague and/or changing expectations and requirements.
Cultural resources that foster cultural continuity and healing were valued by the mothers, who found that positive cultural influences assisted them in regaining a sense of cultural identity and assisted in negotiating cultural conflicts. Mothers reported gaining strength from traditional cultural ceremonies and indicated a desire to pass on the benefits of their cultural identity and traditions to their children. Furthermore, mothers experienced greater empathy and a shared sense of history when service providers were of a similar cultural background. Cultural conflicts, however, of various types, were experienced by the mothers, none of which had been directly addressed by any service providers. This clearly indicates a gap in present service provision.

Furthermore, the need to ensure access to services needs to be addressed. In many instances this includes the necessity of meeting concrete needs such as transportation, clothing, or access to telephones. In other instances this requires modification of program intake criteria to include other family members that are important mothers..

Finally, it is particularly important to understand the impact of poverty on this population. The urban Aboriginal mothers in this study indicated that they feel lucky when they get things they need, blame themselves for financial difficulties, and feel that the failure to get needs met is due to racism. The extent of self-blame is noteworthy given the reality that Income Assistance rates place all families below the poverty line. Insufficiency of funds thus virtually ensures major difficulties in meeting basic family needs. Mothers benefit from messages that their situation is difficult, and from acknowledgment of their efforts to secure the best possible outcomes for their children Mothers also appreciated assistance in dealing with the 'isms,' as acknowledgement of their experiences of stigmatization due to culture or class.

Ultimately, there is a need for comprehensive services that are adequately funded to meet the real needs of clients, and that are culturally appropriate to the client group. Furthermore, there is a need to restructure social programs to elevate those is need out of dire poverty. Family preservation services are not sufficient to address the inequity experienced by urban Aboriginal mothers, and current cutbacks further reduce the ability of such programs to make a meaningful impact on needs. Most importantly, there is a need to include service users in the design, 


\section{The Impact of Poverty on First Nations Mothers Attending a Parenting Program}

delivery, monitoring and evaluation of programming, as well as in the decision making processes associated with funding and social service policies.

\section{References}

Anderson, K. (1998). A Canadian Child Welfare Agency for Urban Natives: The Clients Speak. Child Welfare, 77(4), pp. 441-460.

Belsky, J. (1993). Etiology of Child Maltreatment: A Developmental - Ecological Analysis. Psychological Bulletin, 114(3), pp. 413-434.

Bennett, M. (N. D.). First Nations Fact Sheet: A General Profile on First Nations Child Welfare in Canada. First Nations Child \& Family Caring Society of Canada.

Blackstock, C., Clarke, S., Cullen, J. D'Hondt, J., and Formsma, J. (2004). Keeping the Promise. Ottawa: First Nations Child and Family Caring Society of Canada.

Blackstock, C., N. Trocmè and N. Bennett (2004). Child Maltreatment Investigations Among Aboriginal and Non-Aboriginal Families in Canada, Violence Against Women, 10(8), pp. 901-916.

Coleman, H., Unrau, Y. and Manyfingers, B. (2001). Revamping Family Preservation Services for Native Families. Journal of Ethnic and Cultural Diversity in Social Work, 10(1), pp. 48-68.

Fox, K. (2004). Are They Really Neglected? A Look at Worker Perceptions of Neglect through the Eyes of a National Data System. First Peoples Child \& Family Review, 1(1), pp. 73-82.

Government of Canada. (2005). Child and Family Services Statistical Report 1998-1999 to 2000-2001. Retrieved Mach 1, 2005, from http://www11.sdc.gc.ca/en/cs/ sp/sdc/socpol/publications/statistics/2004-002599/ page00.shtml.

Joseph, R. (1999). Healing Ways: Aboriginal Health and Service Review. Vancouver, BC: Vancouver Richmond Health Board.

Kline, M. (1993). Complicating the Etiology of Motherhood: Child Welfare Law and First Nation Women. Queen's Law Journal, pp. 306-342.

Mandell, D., Carlson, J., Fine, M. and Blackstock, C. (2003). Aboriginal Child Welfare. Partnerships for Children and Families Project. Kitchener: Wilfred Laurier University. Available online at: http://192.54.242.121/ documents/7179/Aboriginal_child_welfare.pdf.
Mann, M. (2005). Aboriginal Women: An Issues Backgrounder. Ottawa: Status of Women Canada.

McKenzie, B. and Hudson, P. (1985). Native Children, Child Welfare, and the Colonization of Native People. In K. L. Levitt \& B. Wharf (Eds.), The Challenge of Child Welfare, pp. 121141. Vancouver, BC: University of British Columbia Press.

Pelton, L. (1997). Child Welfare Policy and Practice: The Myth of Family Preservation. American Journal or Orthopsychiatry, 67(4), pp. 545-553.

Timpson, J. (1995). Four Decades of Literature on Native Canadian Child Welfare: Changing Themes. Child Welfare, 74(3), pp. 525-546.

Trocmè, N. et. al., (2003). Canadian Incidents Study of Reported Child Abuse and Neglect - 2003: Major Findings. Ottawa: Public Health Agency of Canada.

Trocmè, N., Knoke, D. and Blackstock, C. (2004). Pathways to the Overrepresentation of Aboriginal Children in Canada's Child Welfare System. Social Service Review, pp. 577-600.

Walmsley, C. (2005). Protecting Aboriginal Children. Vancouver: UBC Press. 